\title{
Challenge, response and serendipity in the design of materials
}

\author{
R W CAHN \\ Department of Materials Science and Metallurgy, University of Cambridge, Pembroke Street, \\ Cambridge CB2 3QZ, England
}

\begin{abstract}
A number of condensed case-histories of successful materials innovations are presented to illustrate the author's thesis that happy accident favouring the prepared mind (i.e. serendipity), or alternatively a response to a challenge from competing materials, are circumstances favouring effective innovation.
\end{abstract}

Keywords. Case histories; age-hardening; transformer laminations; lamp filaments; nanostructures and nanofilters: superalloys; strong fibres.

\section{Introduction}

The British historian Arnold Toynbee, in his ambitious multivolume History of the World, introduced the concept of 'challenge and response', the notion that throughout history, one nation, one class, one religion, one army, challenged another and was met, usually, by a forceful response to the challenge. In this way, empires, civilizations, religions and dominant classes alternated, according as the challenge or the response prevailed. The same thing has happened, in a less dramatic form, in the development of new materials. One family of materials (for instance, silicon-iron in transformer laminations) had the market to itself for a long time, and nothing much changed for many years; then a challenger came with better properties (here, metallic glass) and the makers of the dominant material responded in panic by improving their ancient product in a hurry. The response would not have happened without the challenge.

But not all innovations are determined by this kind of 'force of arms': accident plays its part in this process, as it does in all aspects of human life. As we know, 'accident favours the prepared mind', and if accident, mental preparedness and sheer good luck come happily together, what we get is serendipity. This curious word derives from the legendary Prince Serendip of old Ceylon, who always had flawless good luck (that is why he was legendary). Serendipity requires good luck, but that is never enough: the innovator must be able to recognize what is staring him in the face, and that in turn requires years of experience, plus open-mindedness. Many important materials innovations stem from sheer serendipity. I outlined some of these a few years ago in another Indian publication (Cahn 1981).

\section{Serendipity}

\subsection{Age-hardening}

Age-hardening was discovered, as every student of metallurgy learns in his first undergraduate year, by Alfred Wilm, the head of a newly established metallurgical section in a German government research institute near Berlin in 1906 (though in the leisurely manner of those days, he did not publish his findings for another five 
years after that). In the course of a wholly empirical search for strong aluminium alloys, he was examining an alloy containing $4 \mathrm{wt} \%$ of $\mathrm{Cu}, 0.5 \mathrm{wt} \%$ of $\mathrm{Mg}$ and $0.5 \mathrm{wt} \%$ of $\mathrm{Mn}$, in the cast-and-rolled condition (later it came to be called 'duralumin'). $\mathrm{He}$ examined its indentation hardness on a Saturday, went off for a leisurely weekend (yes, metallurgists had leisure in those far-off days) and on returning next Monday, he repeated his measurements, just to be sure. The alloy was now $40 \%$ harder than before. Wilm knew better than to shrug off this finding as a result of mere careless measurement. He repeated the experiment properly and determined the first agehardening isotherm. By 1914, duralumin was being used to build airships to bombard the British enemy.

This discovery was clearly serendipitous, but not sufficiently so, because there was no basis available for finding any other age-hardening alloys. The Harvard metallurgist Albert Sauveur reported to the US Air Service in 1918 that he did not know of any other metal or alloy exhibiting a similar phenomenon, so that analogy did not help. Thereupon, in 1919, Paul Merica, a metallurgist at the National Bureau of Standards in Washington, studied the solubility of copper (Wilm's predominant solute) in aluminium as a function of temperature, using simple optical micrography, and found that the solubility increased sharply with rising temperature (Merica et al 1920). The secret of age-hardening was now manifest: it clearly depended upon the precipitation of the equilibrium phase from a supersaturated solid solution (in duralumin this happens slowly at room temperature, highly surprising in itself). Of course, like all confident generalizations, this one was only partly true: in fact, it is a metastable precursor of the stable phase, $\mathrm{CuAl}_{2}$, that achieves the hardening, and by the time the stable phase forms, it is all over. Also, we now know that much of the hardening in this particular alloy comes from the precursor of the $\mathrm{Mg}_{2} \mathrm{Si}$ phase rather than from $\mathrm{CuAl}_{2}$; the $\mathrm{Si}$ here was an unintended and unsuspected impurity. No matter, once it was known that an increasing solubility with rising temperature was the key, a simple inspection of phase diagrams, or a few days' work to establish the relevant part of a new phase diagram, sufficed to point the finger at new potential age-hardening systems. Serendipitous observation always needs to be supplemented by systematic investigation.

Wilm's original paper of 1911 appears in translation in an excellent little book by Martin (1968).

\subsection{Electric light filaments}

When Edison invented the incandescent electric lamp, he was plagued by endless difficulties with his filaments; he began with charred organic material and never managed to produce an effective metallic filament. That achievement fell to William Coolidge, the legendary metallurgist who eventually directed the General Electric Research Laboratory in Schenectady, NY (he also gave his name to the modern type of X-ray tube). In 1913 Coolidge took out a US patent on ductile tungsten, made by powder metallurgy, which allowed ultrafine filaments to be drawn down from a metal rod. For such filaments to be useful, they had to have a long life. Two features were noted to limit this life: one was evaporation from the tungsten to deposit on the lamp envelope, which soon became opaque (even before the tungsten all evaporated away), the other was the white-hot filament slipping apart along grain boundaries. Irving 
Langmuir, the Nobel-prize-winning physical chemist who was Coolidge's most distinguished colleague, cured the first problem by filling the lamp with a noble gas. The second problem was far more difficult, and Coolidge solved it by a classic exercise in serendipity. He noted that tungsten powder annealed in one particular make of crucible, imported from Germany, after sintering and drawing down did not have the grain-boundary problem, and micrographic examination showed that in this batch, the grain boundaries were all longitudinal: this proved to be the essential microstructure that conferred long life on the filaments. Next, Coolidge followed up his lucky accident with systematic work: the successful tungsten powder was analysed and found to contain potassium and aluminium silicate, picked up from the refractory. Thereafter, small amounts of these 'dopants' were added intentionally to the tungsten powder (with a shovel, on the shop floor); this is still done today (to the tungsten oxide precursor), even if a shovel is no longer used! The long-lived Coolidge, who became a centenarian, described his inspired innovation in a historical book published in 1965 (Coolidge 1965), but he still did not know, 52 years later, why his dopant worked so well. It was discovered subsequently, by TEM, that the dopant produces microbubbles of potassium vapour during sintering and the drawing process draws these out into strings which act to constrain migration of the grain boundaries and thus to achieve the required microstructure. The three doping constituents were needed to generate a fairly stable compound which only releases potassium vapour at a late stage in sintering, when porosity has become closed. Here, as so often in the history of materials technology, the scientific explanation came long after successful practice was established. The historical stages, of both the technology and the science of tungsten lamp filaments, have been very clearly outlined by Welsch and Walter (1990).

\subsection{The beginnings of superalloys}

The development of the gas turbine, to power a jet engine, began independently in England and Germany at the end of the 1930s; from an early stage it had become clear that an utterly novel type of alloy would be required for the turbine blades and disc and this led to a crash programme of alloy development, of what came to be called 'superalloys'. The English side of this programme has been described by one of the chief protagonists, L B Pfeil (Pfeil 1963), and an outline of this work and of the slightly later stages of superalloy improvement has been presented in a more accessible publication by Cahn (1973).

Like the discovery of age-hardening and of ductile sintered tungsten, superailoy development began with a happy accident, acutely observed by a 'prepared mind'. Development had begun with tests of $80 / 20$ nichrome, long used for the filaments of domestic electric heaters. Different batches did not behave consistently and the best behaviour was traced to batches which had been contaminated with titanium and a little carbon, because of deoxidation of the melt with titanium (not a universal practice). Thereupon the titanium content was intentionally increased and further improvement in properties resulted. There were still surprising variations and at this stage a little science was injected, in the form of the determination of some partial ternary phase diagrams. A working hypothesis was now formulated, that of 'marginal solubility': the idea was that the best creep resistance required alloys with just more of each solute than was soluble at the service temperature; this idea arose because 
it had become clear that effective age-hardening alone was not enough to guarantee good creep resistance. That working hypothesis proved to be rather too simple, but meanwhile it served as an 'energizer'. This often happens in materials research as it does in ordinary human life: a false hypothesis leads to action which eventually reveals a better hypothesis. Another accident based on a false hypothesis led to the introduction of aluminium into superalloys, probably the most important improvement of all. That in turn led Taylor and Floyd (1951-52) to one of the great classics of phase diagram research, on the $\mathrm{Ni}-\mathrm{Al}-\mathrm{Ti}$ system, in which they were able to show that $\mathrm{Ni}_{3}(\mathrm{Al}, \mathrm{Ti})$ was the crucial precipitating phase. Hereafter, development became ever more science-based, with studies of lattice parameter misfit between the ordered and disordered phases as a function of alloying strategy and of the factors, including small misfit, that so effectively stabilize the ordered $\mathrm{Ni}_{3}(\mathrm{Al}, \mathrm{Ti})$ dispersion against Ostwald ripening. These stages, leading to the successive members of the famous NIMONIC series of superalloys manufactured in England, are described in Cahn's overview (Cahn 1973).

A recent, systematic survey of superalloys (Tien and Caulfield 1989) fails to mention any aspect of the early development and presents superalloys as though they were an exclusively science-based success story; but then this volume is fixated on the American end of the superalloy story and the name 'NIMONIC' never appears in the book! Generally, many scientists are shy about citing any reference more than ten years old lest they be thought out of date and (worse) backward-looking; but by this omission, they fail to learn from history.

\subsection{Nanofilters}

In 1967 the second major report from the US National Academy of Sciences to the US House of Representatives, following a formal agreement between the two bodies in 1963, was published in Washington (Committee on Science and Public Policy 1967). This was entitled Applied Science and Technological Progress, and it was the first of several memorable reports of this kind with a close bearing on materials. This report, which is very little known and was hard to obtain even at the time, deserves renewed attention, maybe even republication. It includes, among many other items worth reading, a splendid historical overview by Cyril Stanley Smith and thoughtprovoking essays by people like Harvey Brooks, Edward Teller, Alvin Weinberg and others. However, from my present perspective, the key chapter is one by C Guy Suits and Arthur $M$ Bueche, both past directors of research at General Electric in Schenectady, NY. Their title is "Cases of research and development in a diversified company'.

The fascinating chapter records in detail the history of 10 innovations, most of them concerned with materials, and then goes on to draw a number of broad conclusions about the sources and uses of applied research and about the role of patents. Each record starts with a narrative account of the sequence of events and concludes with a list of key personnel (with a few words about each individual), a list of patents issued and of some key publications. GE has for many years employed a professional historian on its staff, and his influence is clearly visible in the chapter; it would be a fine thing if more major companies followed this policy. (Elsewhere, I have tried to place this practice of recording case histories of innovation in a broader 
perspective (Cahn 1970)). Innovations here treated include, inter alia, artificial diamonds (a splendid case of challenge and response) - today one might add thin-film diamond and isotopically enriched diamonds to this story - and also a vacuum circuit breaker (a major industrial product) which turned out to depend entirely on the use of zone-refined copper to eliminate degassing of the electrodes in their permanently sealed vacuum enclosure. This crucial innovation took some 40 years to reach a successful conclusion and incidentally represents the only recorded useful application of zone-refined metals, as opposed to semiconductors. Yet another very major innovation described here in some detail was the creation of a large new industry, the production of high temperature vapour lamps, with translucent alumina envelopes (glass or silica were useless), all springing from some fundamental research on the mechanism of sintering of alumina powder. This again was a classic example of serendipity, arising out of a chance encounter between ceramic researchers and a lamp engineer.

However, the most extraordinary episode recorded in the chapter refers to 'etched particle tracks'. The work in question was undertaken in the 1960 s by three wellknown physicists on the GE staff, R M Walker, P B Price and R I Fleischer. Suits and Bueche raise the question of why such very 'pure' research should be undertaken in an industrial laboratory. Part of their answer is: '... experience has shown repeatedly that studies begun solely to grapple with fundamental questions of science can be rewarding to industrial technology, providing advances for which there was no pre-existent need [my italics], however strong that "need" might become afterwards'. I wonder how many research directors would dare say this today! The original objective was to develop and study cosmic ray-tracks in meteorites, and thereby develop a new method of geological and cosmological dating; in this it was successful. Part of the research involved the creation of artificial tracks, by shooting fission fragments from uranium through thin slivers of mica and 'developing' the tracks chemically. As a sideline, the investigators exploited their finding that an irradiated and etched mica sliver contained minute, submicron holes all exactly the same size. By word of mouth this work came to the ears of a cancer researcher in New York, who needed to isolate and detect cancer cells in blood by filtering the blood through sieves that would hold back the larger, more rigid cancer cells while allowing smaller cells to pass through. Fleischer thereupon sought materials less fragile than mica to use for making such sieves, and found that GE's own patented polymer, Lexan ${ }^{\mathrm{TM}}$ polycarbonate, served very well. The upshot was the creation of a small but lucrative industry manufacturing Nuclepore ${ }^{\mathrm{TM}}$ filters for biomedical research; this manufacture is still in existence and has broadened into several companies. This is one of the most convincing instances of serendipity known to me.

\subsection{Ashless polymers}

The commercially trained eye can often see possibilities that would never occur to the cloistered academic. A good instance of this comes from a small company in Pennsylvania. J U Santangelo in this company exploited chemical researches done in Japan in the mid 1960 s on copolymerization of epoxies with carbon dioxide to produce commercially a family of polymers consisting about $50 \%$ of $\mathrm{CO}_{2}$; these are generically named poly(alkylene carbonates) (Santangelo and Tao 1990). 
Thermogravimetric analysis of such polymers (a normal investigative technique to check on thermal stability) showed that they decompose and burn cleanly at around $240^{\circ} \mathrm{C}$. What was unusual, and perhaps to be expected in materials containing so much $\mathrm{CO}_{2}$, was that the material left virtually no ash at all, less than $2 \mathrm{ppm}$. Accordingly, Santangelo is offering this product as an ashless binder for ceramic and metal powders that are to be sintered, and as a substitute for expanded polystyrene in lost-foam casting.

The foregoing examples indicate what a wide variety of innovations have resulted from serendipitous observations.

\section{Challenge and response}

\subsection{Transformer laminations}

In 1899, Barrett and Hadfield in England stumbled upon the fact that silicon-iron containing $3-3.5 \mathrm{wt} \%$ of silicon shows low hysteresis when magnetized, and is also easy to process because the silicon suppresses the ferrite-austenite transformation. Ever since, silicon-iron sheets, coated with insulator to reduce eddy currents, have been used to make transformer laminations. It is a very large industry indeed, worldwide.

The magnetic characteristics of silicon-iron strip were further improved when Goss found how to generate a (110)[001] texture by secondary recrystallization, which was beneficial because of the anisotropy of permeability in iron crystals. Between 1968 and 1977 various companies in Japan and the USA found ways of sharpening the texture, thereby achieving some further improvements in magnetic performance (Luborsky et al 1983); this work was clearly stimulated by normal commercial competition between rival manufacturers.

Enter, stage left, the challenger. In 1958, Pol Duwez in California, with his collaborators, discovered the first melt-quenched metallic glass in the Au-Si system (see historical overview by Cahn (1993)), and the same year Gubanov in Russia first suggested that a metallic glass should be capable of having ferromagnetic properties, an idea which had not occurred to anyone previously. This was soon confirmed experimentally with iron- and cobalt-rich glasses. There was a gap of some years before this idea was followed up, but from the beginning of the 1970s research gathered pace and in 1973 the first multiauthor volume on 'Amorphous Magnetism' was published. By the beginning of the 1980s, the subject had become firmly established, with numerous research teams across the world. Furthermore, several manufacturers had begun to produce sheets of 'soft' ferromagnetic glasses with high permeability and low coercive field, up to a foot or so in width, using ingenious developments in rapid solidification technology; one American firm was particularly aggressive in this field. It was striking that three distinct research teams independently optimized the composition of such glass for transformer uses and came up with virtually identical compositions based on $\mathrm{Fe}-\mathrm{Si}-\mathrm{B}$ with, sometimes, a little carbon. Such glasses have the following advantages over silicon-iron: no appreciable intrinsic anisotropy of permeability (although a favourable anisotropy can be induced by field-annealing), very low intrinsic magnetic losses, a high electrical resistivity which reduces in-plane eddy current losses. A disadvantage is the fact that the saturation magnetization is somewhat lower than in crystalline alloys. Overall, the core loss in 
metallic glass laminations was found to be an order of magnitude lower than for $3 \mathrm{wt} \%$ silicon-iron.

At this point, the transformer manufacturers began showing serious interest, especially in the US and Japan in connection with 'distribution transformers', which are located near individual consumers to transform voltage down to $110 \mathrm{~V}$ (this market does not exist in Europe). Such transformers are small enough to utilize the glass sheet with its limited width, and enormous numbers are required every year. The Electric Power Research Institute in California commissioned a large-scale industrial trial of metallic glasses in these products.

Starting from about 1980 , the steelmakers read the writing on the wall, and began to fight back. The first approach was to try to increase the silicon content in (crystalline) silicon-iron, thereby enhancing the resistivity and thus reducing eddy currents. Ironically, to achieve this the steelmakers exploited the same technique which made metallic glasses possible, namely rapid solidification processing (RSP). Up till then, $3.5 \mathrm{wt} \%$ was the practical limit of silicon concentration, since any more than this led to great brittleness so that the alloy could not be rolled into sheet. RSP allowed ductile silicon-iron to be made with up to $6.5 \mathrm{wt} \%$ of silicon. Usually this was without texture (a weakness), but with elaborate processing involving several rollings and anneals, an ideal (100)[001] texture could be achieved, albeit at considerable cost (e.g. Kan et al 1982). In 1982, the commercial price of metallic glass sheet was still about 10 times that of the cheapest oriented iron-silicon sheet, so the steelmakers' alarm might have seemed premature. However, as shown by Smith (1993), by 1990 the price differential had disappeared, as indeed the glass manufacturers had predicted six years previously. It seemed that the $3.5 \rightarrow 6.5 \%$ solute shift was not enough to fight off the challenge (although Smith suggests that the enriched silicon-irons may have a rosy future in electric motor laminations, where price is considerably more important than performance).

In the late $1980 \mathrm{~s}$, accordingly, the steelmakers (especially those in Japan) became more sophisticated. A good example can be seen in a paper by Inokuti et al (1992), entitled 'Grain-oriented silicon steel sheet with new ceramic films characterized by ultra-low iron loss'. This work refers to commercial $3.3 \mathrm{wt} \%$ silicon-iron with the usual Goss texture. The sheet was chemically polished and then either $\mathrm{CrN}$ or $\mathrm{TiC}$ was ion-plated (physically deposited with a hollow cathode discharge) on the sheet while that was held under tension. The result was that the surface layers of the sheet were under strong tension and this led to a sharply reduced stress dependence of magnetostriction and in turn to a $40 \%$ reduction in core loss. Coatings to enhance surface stress have long been used, but this approach takes the technique to a new level of sophistication. Nothing is said about commercial costs, so one cannot judge how this approach changes the commercial balance sheet! The battle continues.

\subsection{Strong fibres}

Fibre-reinforced composites with polymeric, metallic or ceramic matrices are being improved constantly; both strength and temperature capability are constantly being enhanced. The variety of reinforcing fibres available now in the market constitute a prime illustration of challenge and response. The rivals include crystal whiskers (the strongest and the most expensive), ultrafine metal wires, including so-called Taylor wires; glass fibres; boron fibres, usually on a tungsten core; silicon carbide fibres made 
by several distinct processes; carbon fibres, ditto; alumina fibres; and a variety of strong polymeric fibres, notably Kevlar and polyethylene.

Historically, glass fibres for reinforcing cheap epoxy polymers came first, and they continue to hold the less expensive end of the market; the strong polymeric fibres were a response to the dominance of glass, which in turn was improved by composition changes to stand up to the chemical environment of a cement matrix (the cheapest of all). Whiskers (never more than $1-2 \mathrm{~mm}$ in length) created great interest because of their exotic manner of production, but in spite of recurrent flickers of life, they cannot really compete anymore with modern continuous fibres. Carbon fibres made from a polyacrylonitrile precursor started in Japan and were soon perfected in Britain, and increasingly hold the expensive end of the low-temperature market. Later, a challenge came from Japan, where in 1975 Yajima was able to make SiC fibres from a polymeric precursor; it took a long time for these to make inroads in the market, and he became so discouraged that he took his own life. But soon after, his fibres became a commercial success and hold a special place for high-temperature uses. Boron and alumina fibres are even more expensive but are beginning to make inroads in defence uses where cost is secondary. The commercial balance remains uncertain and battle continues.

An early brief critical discussion of alternative fibres came in a special issue of the journal Materials Science and Engineering devoted to 'Challenges and opportunities in materials science and engineering'; the authors were Chou and Kelly (1976). Later, Kelly (1986) critically discussed the modes of manufacture, merits and weaknesses of rival reinforcing fibres and wires in his standard text, while a more recent comparison comes in a new volume on composites (Parvizi-Majidi 1993).

\subsection{Nanostructured WC-Co 'hard metals'}

Nanostructured materials have been the subject of very rapidly increasing research for some seven years now, and in 1991 they achieved the status symbol of their own dedicated journal. I surveyed the early stages in the progress of this impressive bandwagon in 1988 and 1990; these articles have recently been reprinted (Cahn 1992). One of the first proper commercial applications of these materials with submicron-scale microstructures refers to the familiar long-established 'hard metal', widely used for making metal-cutting tools particularly; they consist of hard, brittle tungsten carbide crystals dispersed in a softer, ductile cobalt matrix. This material is facing increasing competition from rivals such as sialon, oxides and indeed diamond layers deposited by CVD: there was thus a good marketing reason for aiming at some kind of major improvement in hard metal.

Kear and McCandlish of Rutgers University in New Jersey have developed such an improvement in the past four years, and have reported on it in a new journal (Kear and McCandlish 1993). Normally, a hard metal block is made by co-sintering (and perhaps hot isostatically pressing) a mixture of WC and Co powders, and the microstructure is quite coarse. Kear and McCandlish learnt from chemical engineering practice and started from an organometallic precursor, cobalt tris(ethylenediamine) tungstate, which after spray-drying and then thermochemical conversion in a fluid bed reactor gave WC- $23 \mathrm{wt} \% \mathrm{Co}$ powder. Careful control of gas composition and temperature to achieve rapid and controllable carburization was an essential component 
of the process. The incorporation of some VC to inhibit grain growth was found essential. In this way, a very fine-structured product can be made, and this, as expected, resisted cracking to much higher stresses than the conventional product. This in turn allows faster machining when the new product is used for cutting tools. Kear and McCandlish opine that their 'spray conversion processing' has much unrealized potential for producing other flaw-free, nanostructured materials also.

\section{Conclusions}

These few instances of my two categories of innovative materials could be multiplied manyfold. Some are at an early stage, such as systematic design of advanced steels from first principles or the production of diamond films from the vapour phase, others are further developed, such as magneto-optical memories for computers.

I would leave the reader with one thought. Too few academic groups and indeed industrial companies keep detailed records of the kind that would permit systematic historical accounts of the genesis, growth and maturity of a new product to be assembled, in the way that GE was able to do in the 1960's. The whole research and development community has much to learn from such accounts: perhaps there is a case to be made for government financing of such innovative histories, and perhaps of comparative studies of success and failure of innovation. As recorded in my 1970 paper (Cahn 1970), in the 1960s there were many such studies; perhaps today we are too surfeited with a mass of information to cope with. But it is precisely at such a time that reviews, surveys and concise histories are particularly valuable. Perhaps it is time to start again.

\section{Acknowledgement}

I am grateful to Prof. C J Humphreys for his welcome in Cambridge and for providing facilities for this paper to be written.

\section{References}

Cahn R W 1970 Nature (London) 225693

Cahn R W 1973 J. Met. (AIME) 1

Cahn R W 1981 in Alloy design (eds) S Ranganathan, V S Arunachalam and R W Cahn (Bangalore: Indian Academy of Sciences) pp. 3-8

Cahn R W 1992 Artifice and artefacts (Bristol and Philadelphia: IOP Publishing) pp. 32, 43

Cahn R W 1993 in Rapidly solidified alloys (ed.) H H Liebermann(New York: Marcel Dekker) pp. 1-16

Chou T W and Kelly A 1976 Mater. Sci. Engn. 2535

Committee on Science and Public Policy of the U.S. Academy of Sciences 1967 Applied science and technological progress (Published for the Committee of Science and Astronautics of the US House of Representatives) pp. 297-346

Coolidge W D 1965 in The Sorby Centennial Symposium on the History of Metallurgy (ed.) C S Smith (New York: Gordon and Breach) pp. 443-449

Inokuti Y, Suzuki K and Kobayashi Y 1992 Mater. Trans. Jpn. Inst. Met. 33946

Kan T, Ito Y and Shimanaka H 1982 J. Magn. Magn. Mater. 26127

Kear B H and McCandlish L E 1993 Nanostructured Materials 319

Kelly A 1986 Strong solids (Oxford: Clarendon Press) 3rd edition ch. 7 
Luborsky F E, Livingston J D and Chin G Y 1983 in Physical metallurgy (eds) R W Cahn and P Haasen (Amsterdam: North-Holland) 3rd edition p. 1703

Martin J W 1968 Precipitation hardening (Oxford: Pergamon Press) pp. 103-114

Merica P D, Waltenberg R G and Scott H 1920 Trans. AIME 6441

Parvizi-Majidi A 1993 in Structure and properties of composites (ed.) T W Chou vol. 13 of Materials science and technology (eds.) R W Cahn, P Haasen and E J Kramer (Weinheim: VCH) pp. 25-88

Pfeil L B 1963 in Advances in materials research in the NATO nations (ed.) H Brooks et al (published by Pergamon Press for AGARD) p. 407

Santangelo J U and Tao J C 1990 in Supplementary Volume 2 to the Encyclopedia of materials science and engineering (ed.) R W Cahn (Oxford: Pergamon Press) pp. 1192-1196

Smith C H 1993 in Rapidly solidified alloys (ed.) H H Liebermann (New York: Marcel Dekker) pp. 617-663

Taylor A and Floyd R W 1951-52 J. Inst. Met. 80577

Tien J K and Caulfield T 1989 Superalloys, supercomposites and superceramics (San Diego: Academic Press)

Welsch G and Walter J L 1990 in Supplementary Volume 2 to the Encyclopedia of materials science and engineering (ed.) R W Cahn (Oxford: Pergamon Press) pp. 1007-1012 